Pak. j. sci. ind. res. Ser. B: biol. sci. 201255 (3) 159-165

\title{
Qualitative Assessment of Bacteria and Fungi in the Indoor Environment of Hospitals of Islamabad, Pakistan
}

\author{
Fouzia Hussain*, Subhe Sadiq Tahir, Naseem Rauf and Afifa Batool \\ Environmental Analytical Laboratory, PCSIR, 16, H-9, Islamabad, Pakistan
}

(received October 31, 2011; revised June 29, 2012; accepted August 10, 2012)

\begin{abstract}
This study was conducted to determine the health risks in the indoor air of the four government hospitals of the Islamabad city, Pakistan. Four different main wards, i.e., general male/female surgical wards, children's ward and microbiology laboratory were included. The sampling was done in the summer season due to the possibility of maximum recovery of microorganisms. Results showed presence of bacterial and fungal pathogens in the air of hospitals especially in surgical wards of all hospitals. Lowest bacterial counts were recorded in microbiology laboratory. Among bacterial isolates Micrococcus and Staphylococcus aureus were abundantly found in all hospitals as $22.09 \%$ \& $21.2 \%$, respectively followed by gram negative group of bacteria i.e, Enterobacteriaceae spp. (Escherichia coli), Pseudomonas spp. were found to be lowest as $6.5 \%$ of the total bacterial load in all hospitals. Among the fungi Aspergillus (fumigatus, niger, flavus) recovery was the most in the environment of all hospitals with the value of $27.7 \%$ and Tricosporon was observed lowest with the value of $1.15 \%$. p- value for total microbial load among the hospitals sampled was not significant.
\end{abstract}

Keywords: bacteria, fungi, hospitals, indoor air.

\section{Introduction}

Hospital plays significant role in the spread of common nosocomial infections. Bioaerosols are complex mixture of microorganisms, microorganism fragments, and by-products such as molds bacteria, endotoxins, mycotoxins, and volatile microbial organic compounds. Exposure to these microbial fragments and metabolites may result in adverse health effects (Kalogerakis et al., 2005; Nilsson et al., 2004).

Bacteria, fungi and yeast are frequently found in indoor environment and air and act as a medium for their transmission or dispersal. Inhalation, ingestion and dermal contact are the routes of human exposure to airborne microorganisms (Halide et al., 2010; Ki et al., 2010; Fleischera et al., 2006; Marta and Jacek, 2006). Immunocompromised patients may develop pneumonia, asthma and bronchitis by inhaling spores of Aspergillus (Denning, 1998). Up to $80 \%$ of the nosocomial infections are caused by microbes brought with the patient at the time of admission in the hospitals. Remaining $20 \%$ of nosocomial infections result from contact with microbes within the hospital or health care facility (Jeffrey, 2004). The number of airborne microbial organisms increases due to contamination of air ducts for heating, ventilation, and air conditioning system without its regular replace-ment (Anderson et al., 1996).Microbial population level can be influenced by

*Author for correspondence; E-mail: mahiii_qua@yahoo.com many other factors and it increases by organic materials such as food, flowers and fruits brought from outdoor environment by visitors for patients (Schabrun and Chipchase, 2006). Symptoms of dizziness, headache, nausea, irritation of eyes, nose, and throat are due to exposure to unhygienic indoor air quality (Fischer et al., 2008).

Furthermore, controlling microbial load in air of hospitals may play a role in the prevention of cross infections. The aim of present work was to study the indoor air for airborne bacteria and fungi of government and private hospitals in Islamabad in areas such as male and female surgical wards, children's ward and microbiological laboratory and their identification at their genus level.

\section{Materials and Methods}

The present study was carried out in different hospitals of Islamabad city, Pakistan. The samples were collected from four different units of four hospitals. These includes the male ward (surgical), female ward (surgical), children ward and microbiology laboratory.

The sampling was carried out in summer season in the morning between 10-11 am because high level of activity during these hours in the hospital. Nutrient agar plates were used for the isolation of bacteria while potato dextrose agar (chloramphenicol $100 \mathrm{mg}$ added in PDA to suppress the bacterial growth) was used for the 
isolation of yeast and mold. The prepared sterilized plates were allowed to expose for 15-20 min. These plates were brought in clean and sterilized container into the laboratory and were incubated at $35-37^{\circ} \mathrm{C}$ for 24-48 h for bacteria, while PDA plates were incubated at $25^{\circ} \mathrm{C}$ for at least five days (Ekhaise et al., 2008). Colonies on each plate were counted and results were reported as the count of colony-forming units (CFUs) and converted to organisms per cubic meter air. After incubation, according to colony morphology and gram staining of bacteria, organisms were subcultured on to differential growth media. Biochemical tests were performed for further identification of bacterial organisms. Bacteria were identified according to Bergey's manual (Bergey, 1984). The fungal colonies were identified according to the method reported by Barnett and Hunter (1972). The gross morphology of the fungal colony (shape, colour) and microscopic examination of the spore and hyphal characterization was done by using lactophenol cotton -blue solution (Ekhaise et al., 2008). Media and chemicals used for bacterial and fungal studies were purchased from Oxide, UK and Merck, Germany.

Statistical analysis. Statistical analysis including mean, standard deviation and standard error were calculated and level of significance was calculated according to Caulcutt and Boddy (1983). $\mathrm{p}<0.05$ was considered non significant.

\section{Results and Discussion}

In the present study, total of 1783 colonies of bacteria and 433 colonies of fungi were isolated from four hospitals. Seven different genus of bacteria, i.e. Bacillus, Cornybacterium, Micrococcus, Staphylococcus, (S. aureus \& S. epidermidis), Enterobacteriaceae (Escherichia coli), Pseudomonas, Streptococcus and nine genera of fungi, Alternaria, Mucor, Penicillium, Fusarium, Aspergillus (niger, flavus and fumigatus), Cladosporium, Trichosporon, Candida albicans and Rhizopus were isolated. These genera of bacteria and fungi are the most common airborne flora in the studies already reported by Ki et al. (2010); Pakshir et al. (2007); Marta and Jacek (2006); Jaffal et al. (1997).

The recorded levels of microorganisms in female and male surgical wards among all hospitals were higher than those isolated from the children's ward and microbiological laboratory. The results in Table 1 shows the \% of all organisms in which Staphylococcus (34.36 \%, $33.81 \%, 28.48 \%, 36.16 \%)$ and Micrococcus (24.1\%, $22.68 \%, 20.43 \%, 19.31 \%)$ groups were recorded dominant in hospital $\mathrm{A}, \mathrm{B}, \mathrm{C}$, and $\mathrm{D}$, respectively. Micrococcus was encountered in hospital air probably due to its occurrance in a wide range of environments; including water, dust and soil. Both strains of Staphylococcus (coagulase negative and coagulase positive) were isolated. The presence of these isolates in the air can increase the risk of infection since S. aureus are nosocomial pathogens. Gram positive bacteria are normal microbial flora of skin, hair, mucous membrane and other body sites in humans and also present in soil and water, and can easily be airborne (Koneman et al., 1997). Previous studies have also described the wide distribution of this group of bacteria in hospital environment (Halide et al., 2010, Ekhaise et al., 2008; Marta and Jacek, 2006).

Table 1. Total bacterial colonies in \% of all Hospitals

\begin{tabular}{|c|c|c|c|c|c|c|c|c|}
\hline \multirow[t]{2}{*}{ Bacterial isolates } & \multicolumn{2}{|c|}{ Hospital A } & \multicolumn{2}{|c|}{ Hospital B } & \multicolumn{2}{|c|}{ Hospital C } & \multicolumn{2}{|c|}{ Hospital D } \\
\hline & $*_{\mathrm{*}} \mathrm{col}$. & $\%$ & col. & $\%$ & col. & $\%$ & col. & $\%$ \\
\hline Bacillus spp & 97 & 15.8 & 61 & 12.8 & 75 & 20.16 & 39 & 12.15 \\
\hline Cornybacterium & 57 & 9.28 & 39 & 8.19 & 26 & 7 & 31 & 9.66 \\
\hline Escherichia coli & 6 & 0.99 & 7 & 1.47 & 8 & 2.16 & 4 & 1.24 \\
\hline Enterobacteriaceae spp & 11 & 1.79 & 17 & 3.57 & 21 & 5.64 & 18 & 5.6 \\
\hline Micrococcus & 148 & 24.1 & 108 & 22.68 & 76 & 20.43 & 62 & 19.31 \\
\hline Psedumonas & 6 & 0.99 & 8 & 1.68 & 7 & 1.88 & 4 & 1.24 \\
\hline S. epidermidis & 78 & 12.7 & 60 & 12.6 & 27 & 7.26 & 50 & 15.6 \\
\hline S. aureus & 133 & 21.66 & 101 & 21.21 & 79 & 21.23 & 66 & 20.56 \\
\hline Streptococcus spp & 59 & 9.6 & 60 & 12.6 & 39 & 10.48 & 43 & 13.4 \\
\hline Unknown Bacteria & 19 & 3.09 & 15 & 3.2 & 14 & 3.76 & 4 & 1.24 \\
\hline Total & 614 & 100 & 476 & 100 & 372 & 100 & 321 & 100 \\
\hline
\end{tabular}

$*=$ No. of colonies. 
Gram positive bacteria were isolated in higher loads from all hospitals (A, B, C and D) than gram negative group of organisms (Figs.1-4) and this has been previously documented by Ki et al. (2010), Halide et al. (2010) and Jaffal et al. (1997). Gram positive bacteria have strong ability to survive in resistant environment following desiccation, radiation and aerosolized chemical pollutants (Wu et al., 2000). On the other hand pathogenic gram negative bacteria which are associated with wounds and internal body infections are not readily airborne because they may be transmitted directly through physical contact with the infected area (Ekhaise et al., 2008).

In the present study, Enterobacteriaceae spp. were recorded higher in female surgical wards than the male

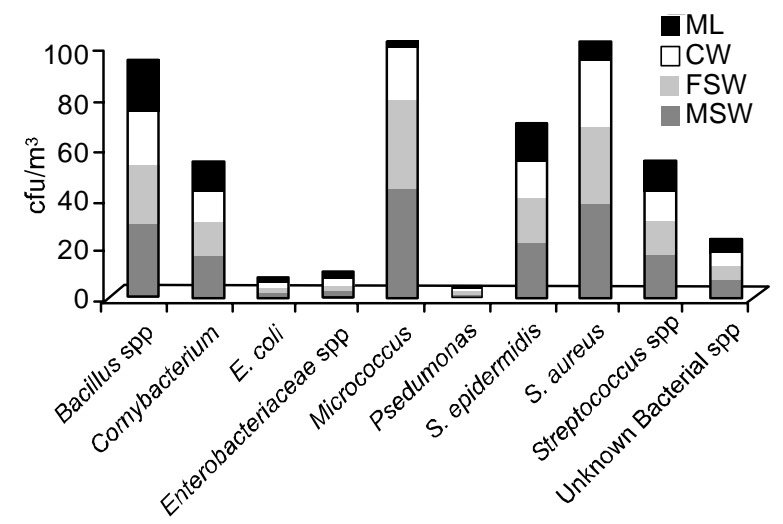

MSW = male surgical ward; FSW = female surgical ward; $\mathrm{CW}=$ children ward; $\mathrm{ML}=$ microbiology laboratory

Fig. 1. Bacterial isolates in Hospital A.

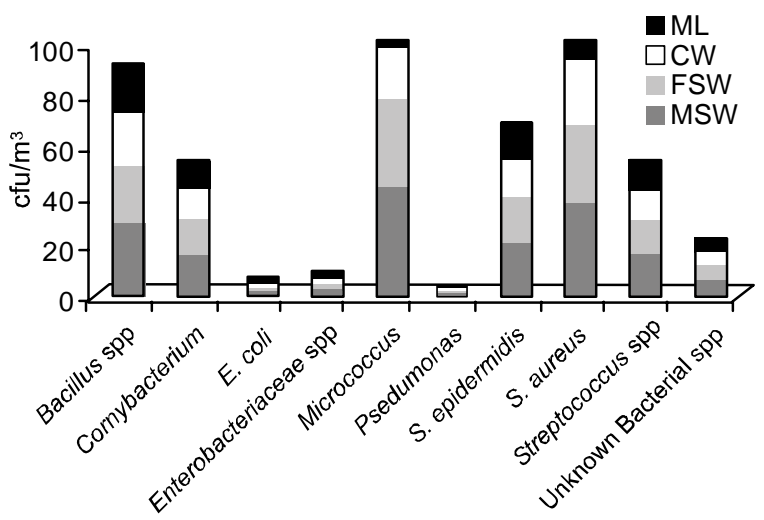

MSW = male surgical ward; FSW = female surgical ward; $\mathrm{CW}=$ children ward; $\mathrm{ML}=$ microbiology laboratory

Fig. 2. Bacterial isolates in Hospital B. surgical wards of all the investigated hospitals because Escherichia coli, Pseudomonas, and Enterobacteriaceae (gram negative group of bacteria) produce endotoxin that possess strong allergens and can cause acute toxic effects, like fever, malasia, decreased pulmonary function and also responsible for urinary tract infection specially in females (Halide et al., 2010, Jeffrey, 2004). Lowest bacterial distribution was observed in the microbiological laboratory as 43cfu, 26cfu, 10cfu and 12cfu in hospital A, B, C, and D, respectively (Figs. 1-4) because of fumigation technique in respective areas. Least bacterial counts in these areas were also recorded by Ekhaise et al. (2008).

Nine different types of fungi were identified in four different units of the hospital. Among which, genus

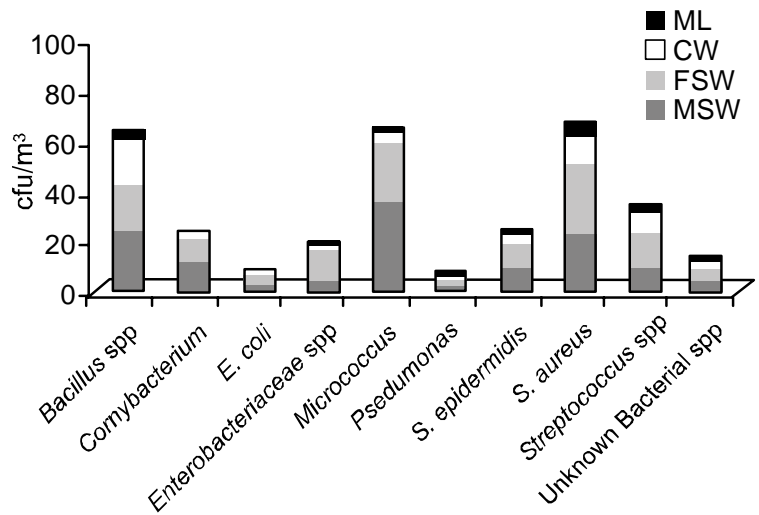

MSW = male surgical ward; FSW = female surgical ward; $\mathrm{CW}=$ children ward; $\mathrm{ML}=$ microbiology laboratory

Fig. 3. Bacterial isolates in Hospital C.

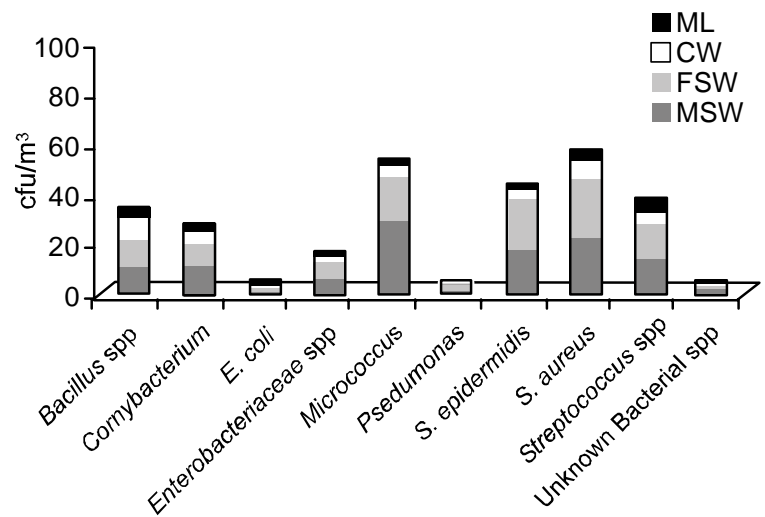

MSW = male surgical ward; FSW = female surgical ward: $\mathrm{CW}=$ children ward; $\mathrm{ML}=$ microbiology laboratory

Fig. 4. Bacterial isolates in Hospital D. 
Aspergillus and its strains (niger, flavus and fumigatus) were found to be dominant as $23.6 \%, 22.7 \%, 29.0 \%$ and $35.1 \%$ in hospital A, B, C, and D, respectively (Table 2). Previously, the prevalence of Aspergillus spores in the hospital environment has been recorded by Kim et al. (2010), Marta and Jacek (2006) and Panagopoulu et al. (2002). Spores of Aspergillus spp. have xerophilic properties, which help them to survive in air for long time (Guinea et al., 2005). A. fumigatus may cause respiratory diseases such as pneumonia, asthma, pulmonary aspergillosis bronchitis, allergic alveolitis and possibly mycotoxicoses in the immunocompromised host (Lacey and Dutkiewicz, 1994; Land et al., 1987).

Cladosporium, Fusarium, Pencillium, Candida albican, Rhizopus, Alternaria and Mucor were also observed in all four hospitals however, no significant trends were observed for other groups of fungi. In Hospital A, Cladosporium spp. (15.26\%), was dominant, while Pencillium and Fusarium (15.9\%) were recorded high in Hospital B. In hospital C, Candida albicans (12 \%) and Rhizopus (12\%) were found high next to Aspergillus genus. The environment of Hospital D was loaded with Rhizopus (14 \%), Cladosporium (13\%) and Fusarium (15\%).

Cladosporium spp. grow well in indoor environment especially in humid surface (Rivas and Thomas, 2005). Airborne spores of Cladosporium and Alternaria are significant and in large amounts they can severely affect asthmatics and in people with respiratory diseases prolonged exposure its may weaken the immune system.
Alternaria may cause hay fever or hypersensitive reactions (Kirk et al., 2008). Our finding is corroborated by previous studies of Pakshir et al. (2007); Martins-Diniz et al. (2005), Pfaller and Wenzel (2003) and Ki et al. (2010).

Trichosporon was also isolated in Hospital A (2.3\%) in male and female surgical ward and in Hospital C (2\%) only in male surgical ward (Table 2). It causes opportunistic infections called trichosporonosis, especially in immunocompromised individuals and has potential to develop resistance to antifungal therapy (Taj-Aldeen et al., 2009; Martins-Diniz et al., 2005). The prevalence of Trichosporon in the air of hospital has been previously recorded (Pakshir et al., 2007; Martins-Diniz et al., 2005). This yeast was not recovered from Hospital B and D.

The distribution of Fungi were higher in surgical wards as compared to children's ward. Fungal isolates were found lowest in number in microbiological laboratory of all hospitals (Figs. 5-8). Surgical wards (male and female both) of hospital A situated in an old building have poor ventilation system and there is no proper control of temperature even in summer season. The level of airborne microorganisms is variable, depending on temperature, relative humidity, time of the day, presence of human activity and artificial climate control. Microbial load may also increase in environment at the time of procedures or handling of contaminated equipments (Jeffrey, 2004). All four studied hospital are surrounded by trees and over crowded by the visitors especially in Hospital A and C. Most of the

Table 2. Total fungal colonies in \% of all Hospitals

\begin{tabular}{|c|c|c|c|c|c|c|c|c|}
\hline \multirow[t]{2}{*}{ Fungal isolates } & \multicolumn{2}{|c|}{ Hospital A } & \multicolumn{2}{|c|}{ Hospital B } & \multicolumn{2}{|c|}{ Hospital C } & \multicolumn{2}{|c|}{ Hospital D } \\
\hline & $*_{\mathrm{col}}$ & $\%$ & col. & $\%$ & col. & $\%$ & col. & $\%$ \\
\hline Alternaria & 12 & 9.16 & 9 & 10.22 & 7 & 7 & 1 & 0.9 \\
\hline Mucor & 16 & 12.21 & 7 & 8 & 8 & 8 & 6 & 5.26 \\
\hline Penicillium & 10 & 7.63 & 14 & 15.9 & 9 & 9 & 11 & 9.64 \\
\hline Fusarium & 14 & 10.7 & 14 & 15.9 & 11 & 11 & 15 & 13.16 \\
\hline A. nigar & 12 & 9.16 & 8 & 9.09 & 9 & 9 & 12 & 10.52 \\
\hline A. flavus & 12 & 9.16 & 4 & 4.54 & 13 & 13 & 19 & 16.66 \\
\hline A. fumigatus & 7 & 5.34 & 8 & 9.09 & 7 & 7 & 9 & 7.9 \\
\hline Cladosporium & 20 & 15.26 & 11 & 12.5 & 10 & 10 & 14 & 12.28 \\
\hline C. albicans & 18 & 13.74 & 9 & 10.22 & 12 & 12 & 13 & 11.4 \\
\hline Trichosporon & 3 & 2.3 & 0 & 0 & 2 & 2 & 0 & 0 \\
\hline Rhizopus & 7 & 5.34 & 4 & 4.54 & 12 & 12 & 14 & 12.28 \\
\hline Total & 131 & 100 & 88 & 100 & 100 & 100 & 114 & 100 \\
\hline
\end{tabular}

$*=$ No. of colonies. 
Table 3. Statistical analysis for total microbial load (Baceria and Fungi) among all Hospitals

\begin{tabular}{|c|c|c|c|c|c|c|c|c|c|c|c|c|}
\hline \multirow[t]{2}{*}{ Parameters } & \multicolumn{3}{|c|}{ Hospital A } & \multicolumn{3}{|c|}{ Hospital B } & \multicolumn{3}{|c|}{ Hospital C } & \multicolumn{3}{|c|}{ Hospital D } \\
\hline & Mean & S.D. & S.E. & Mean & S.D. & S.E. & Mean & S.D. & S.E. & Mean & S.D. & S.E. \\
\hline T. Bacteria & 61.4 & 52.3 & 16.5 & 47.6 & 36.9 & 11.7 & 37.2 & 28.8 & 9.1 & 32.1 & 23.8 & 7.5 \\
\hline T. Fungi & 11.9 & 5.0 & 1.5 & 8 & 4.24 & 1.3 & 9.0 & 3.1 & 0.9 & 10.3 & 5.9 & 1.7 \\
\hline
\end{tabular}

$\mathrm{SD}=$ standard deviation; $\mathrm{SE}=$ standard error.

indoor airborne microorganisms are derived from the outdoor (Schabrun and Chipchase, 2006; Wu et al., 2000).

Statistical analysis. Statistical analysis of the total number of microbes (bacteria and fungi) showed that there was no significant co-relation between all hospitals sampled (Table 3). The p- value was found to be insignificant (Table 4).

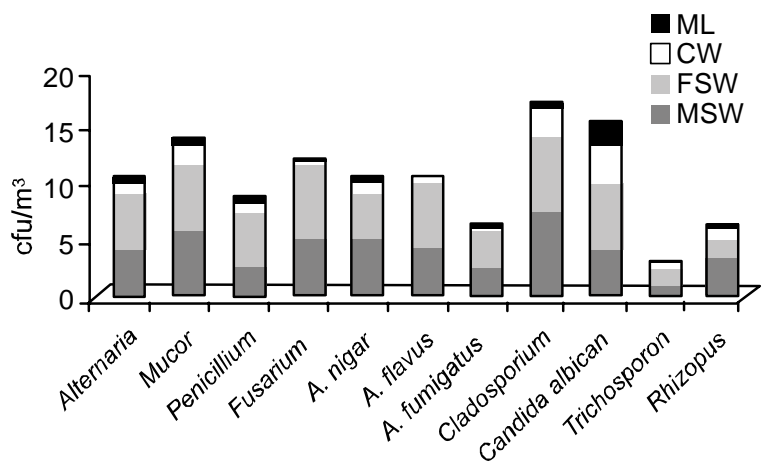

MSW = male surgical ward; FSW = female surgical ward; $\mathrm{CW}=$ children ward; $\mathrm{ML}=$ microbiology laboratory

Fig. 5. Fungal isolates in Hospital A.

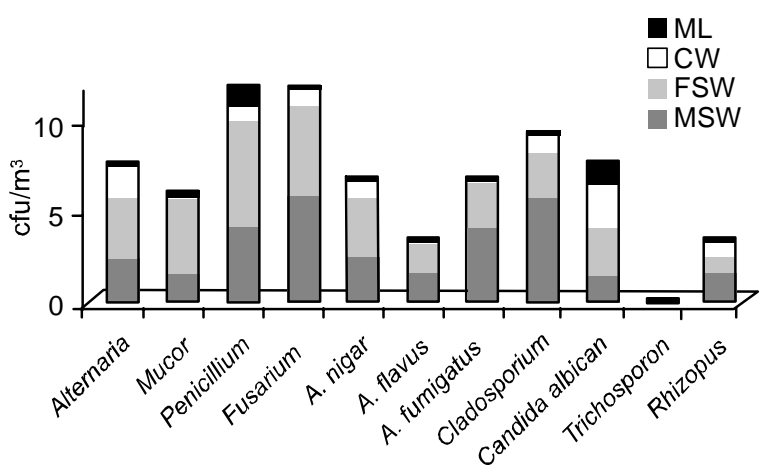

MSW = male surgical ward; FSW = female surgical ward; $\mathrm{CW}=$ children ward; $\mathrm{ML}=$ microbiology laboratory

Fig. 6. Fungal isolates in Hospital B.
Tablle 4. Total bacterial and fungal load in Hospitals A to D

\begin{tabular}{lcc}
\hline \hline Hospitals & \multicolumn{2}{c}{ p-values } \\
\cline { 2 - 3 } & Total bacterial load & Total fungal load \\
\hline Hospital A and B & 0.50 & 0.06 \\
Hospital A and C & 0.21 & 0.13 \\
Hospital A and D & 0.12 & 0.51 \\
Hospital B and C & 0.49 & 0.49 \\
Hospital B and D & 0.27 & 0.29 \\
Hospital C and D & 0.67 & 0.53 \\
\hline
\end{tabular}

$\mathrm{p}<0.05$ considered as non significant.

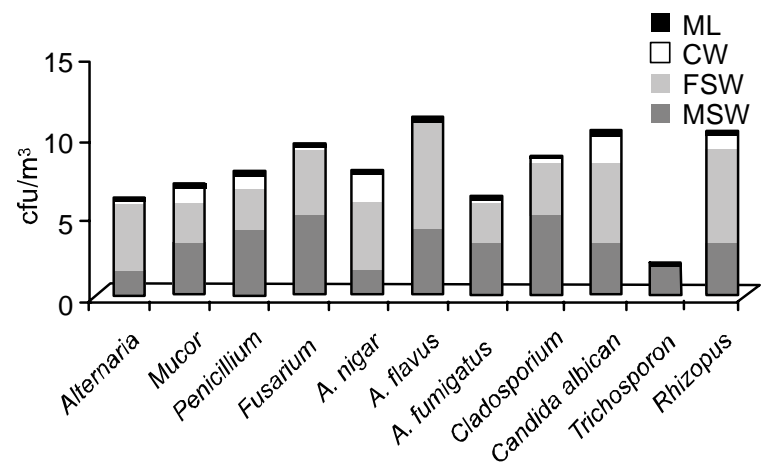

MSW = male surgical ward; FSW = female surgical ward; $\mathrm{CW}=$ children ward; $\mathrm{ML}=$ microbiology laboratory

Fig. 7. Fungal isolates in Hospital C.

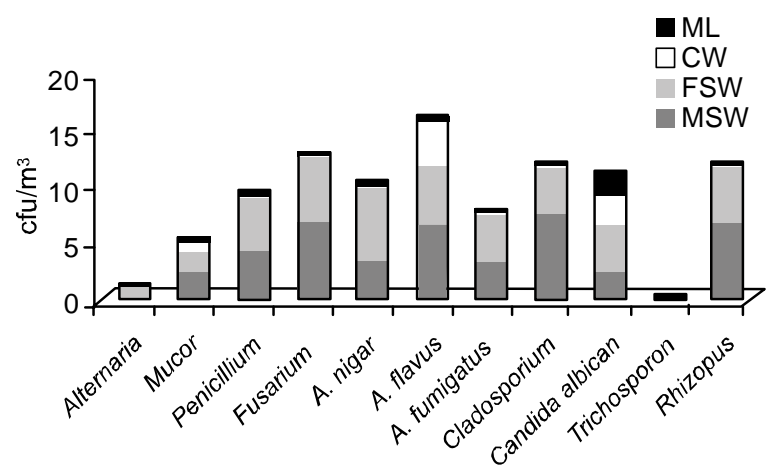

MSW = male surgical ward; FSW = female surgical ward; $\mathrm{CW}=$ children ward; $\mathrm{ML}=$ microbiology laboratory

Fig. 8. Fungal isolates in Hospital D. 


\section{Conclusion}

Present study was carried out to expose some quantitative and qualitative features of hospital environment. The indoor environment of hospital A was more contaminated than Hospital B, C and D. Gram negative microbes, i.e. E. coli, Enterobacteriaceae spp, Pseudomonas were documented in all the hospitals, with higher loads in surgical wards. Similarly, overall more fungal load was documented in the environment of hospital A than any other hospitals under study. Findings of gram negative bacteria and pathogenic fungi in hospital environment indicate the increase health risks especially for immunocompromised patients. The microbiology laboratories of all hospitals showed least microbial growth because of less activity of visitors and use of fumigation technique. Appropriate measures must be taken to reduce the nosocomial infections in hospitals. For reducing the microbial growth, humidity must be controlled in hospitals because airborne microbial flora increases their growth in high humidity. Installation of filtration system (HEPA) and ultraviolet light may be useful for controlling microorganisms in environments where immunocompromised patients are admitted. As microbial load increases the risk to human health and directly related with hygienic level of hospital air, therefore more clinical investigation must be undertaken.

\section{References}

Anderson, K., Morris, G., Kennedy, H., Croall, J., Michie, J., Richardson, M.D., Gibson, B. 1996. Aspergillosis in immunocompromised pediatric patients: association with building hygiene, design, and indoor air. Thorax, 51: 256-261.

Barnett, H.L., Hunter, B.B. 1972. Illustrated Genera Imperfect Fungi, 241 pp., $3^{\text {rd }}$ edition, Burgress Publishing, New York, USA.

Bergey, S.A. 1984. Bergey's Manual of Determinative Bacteriology, $9^{\text {th }}$ edition, Williams \& Wilkins, Philadelphia, USA.

Caulcutt, R., Boddy, R. 1983. Statistics for Analytical Chemist, pp. 6-8, Chapman and Hall Ltd., New York, USA.

Denning, D.W. 1998. Invasive aspergillosis. Journal of Clinical Infectious Diseases, 26: 781-805.

Ekhaise, F.O., Ighosewe, O.U., Ajakpovi, O.D. 2008. Hospital indoor airborne microflora in private and government owned hospitals in Benin City, Nigeria. World Journal of Medical Sciences, 3: 19-23.

Fang, Z., Ouyang, Z.Y., Zheng, H., Wang, X., Hu, L.
2007. Culturable airborne bacteria in outdoor environments in Beijing, China. Microbial Ecology, 54: 487-496.

Fleischera, M., Bober-Gheekb, B., Bortkiewicza, O., Rusiecka-Ziólkowskaa, J., 2006. Microbiological control of airborne contamination in hospitals. Journal of Indoor Build Environment, 15: 53-56.

Fischer, G., Albrecht, A., Jackel, U., Kampfer, P. 2008. Analysis of airborne microorganisms MVOC and odour in the surrounding of composting facilities and implications for future investigations. International Journal of Hygiene and Environmental Health, 211: 132-142.

Guinea, J., Pelaez, T., Alcala, L., Bouza, E. 2005. Evaluation of Czapeck agar and Sabouraud dextrose agar for the culture of airborne Aspergillus conidia. Diagnostic Microbiology and Infectious Disease, 53: 333-334.

Halide, A., Ahmet, A., Muserref, T.O. 2010. Indoor and outdoor airborne bacteria in child day-care centers in Edirne City (Turkey), seasonal distribution and influence of meteorological factors. Journal of Environment Monitoring and Assessment, 164: 53-66.

Jaffal, A.A., Nsanze, H., Bener, A., Ameen, A.S., Banat, I.M., Mogheth, A.A. 1997. Residential indoor airborne microbial populations in the United Arab Emirates. Journal of Environmental International, 23: 529-533.

Jeffrey, C.P. 2004. Alcamo's Fundamentals of Microbiology. $7^{\text {th }}$ edition, Jones and Bartlets Publishing, USA.

Kalogerakis, N., Paschali, D., Lekaditis, V., Pantidou, A., Eleftheriadis, K., Lazaridis, M. 2005. Indoor air quality-bioaerosol measurements in domestic and office premises. Aerosol Science, 36: 751-761.

Kirk, P.M, Cannon, P.F., Minter, D.W., Stalpers, J.A. 2008. Dictionary of the Fungi. pp. 22, $10^{\text {th }}$ edition, Wallingford, CABI, UK.

Ki, Y.K., Yoon, S.K., Daekeun, K. 2010. Distribution characteristics of airborne bacteria and fungi in the general hospitals of Korea. Journal of Industrial Health, 48: 236-243.

Koneman, E.W., Allen, S.D., Janda, W.M., Schreckenberger, P.C., Winn, W.C. 1997. Color Atlas and Textbook of Diagnostic Microbiology, pp. 1395, $5^{\text {th }}$ edition, Philadelphia, New York, USA.

Land, C.J., Hult, K., Fuchs, R., Hagelberg, S., Lundstrom, H., 1987. Tremorgenic mycotoxins from Aspergillus 
fumigatus as a possible occupational health problem in sawmills. Applied Environmental Microbiology, 53: 787-790.

Lacey, J., Dutkiewicz, J. 1994. Bioaerosols and occupational lung disease. Journal of Aerosol Science, 25: 1371-1404.

Martins-Diniz, J.N., daSilva, R.A., Miranda, E.T., Mendes-Giannini, M.J. 2005. Monitoring of airborne fungus and yeast species in a hospital unit. Revista de Saude Publica, 39: 398-405.

Marta, A., Jacek, D. 2006. Variability of airborne microflora in a hospital ward within a period of one year. Annals of Agricultural and Environmental Medicine, (AAEM), 13: 99-106.

Marthi, B., Shaffer, B.T., Lighthart, B., Ganio, L. 1991. Resuscitation effects of catalase on airborne bacteria. Journal of Applied Environmental Microbiology, 57: 2775-2776.

Nilsson, A., Kihlstrom, E., Lagesson, V., Wessen, B., Szponar, B., Larsson, L. 2004. Microorganisms and volatile organic compounds in airborne dust from damp residences. International Journal of Indoor Environment and Health, 14: 74-82.

Pakshir, K., Shekarkhar, G., Mostagnie, S., Sabayan, B., Vaghefikia, A. 2007. Monitoring of airborne fungi in two general hospitals in Shiraz, Southern Iran. Iranian Journal of Medical Sciences, 32: 240-244.

Panagopoulu, P., Filioti, J., Petrikkos, G., Giakouppi, P., Anatoliotaki, M., Farmaki, E., Kanta, A., Apostolakou, H., Avlami, A., Samonis, G., Roilides, E. 2002.
Environmental surveillance of filamentous fungi in three tertiary care hospitals in Greece. Journal of Hospital Infection, 52: 185-191.

Pfaller, M.A., Wenzel, R.P. 2003. The epidemiology of fungal infections, In: Clinical Mycology. E. J. Anaissie, M. R. McGinnis and M. A. Pfaller (eds.), pp. 3-19, Churchill Livingstone, PA, USA.

Pfaller, M.A. 1996. Nosocomial candidiasis emerging species, reservoirs, and modes of transmission. Clinical Infectious Diseases, 22: 89-94.

Rivas, S., Thomas, C.M. 2005. Molecular interactions between tomato and the leaf mold pathogen Cladosporium fulvum. Annual Review of Phytopathology, 43: 395-436.

Schabrun, S., Chipchase, L. 2006. Healthcare equipment as a source of nosocomial infection: a systematic review. Journal of Hospital Infection, 63: 239-245.

Taj-Aldeen, S.J., Nasser, A.A., Sittana, E.S, Jacques, F.M., Ilse, C.B., Bart, T., Teun, B. 2009. Molecular identification and susceptibility of Trichosporon species isolated from clinical specimens in Qatar: Isolation of Trichosporon dohaense Taj-Aldeen, Meis \& Boekhout sp. nov. Journal of Clinical Microbiology, 47: 1791-1799.

Wu, P.C., Su, H.J., Lin, C.Y. 2000. Characteristics of indoor and outdoor airborne fungi at suburban and urban homes in two seasons. The Science of the Total Environment, 253: 111-118.

Wenzel, R.P. 1995. Nosocomial candidemia risk factors and attributable mortality. Clinical Infectious Diseases, 20: 1531-1534. 